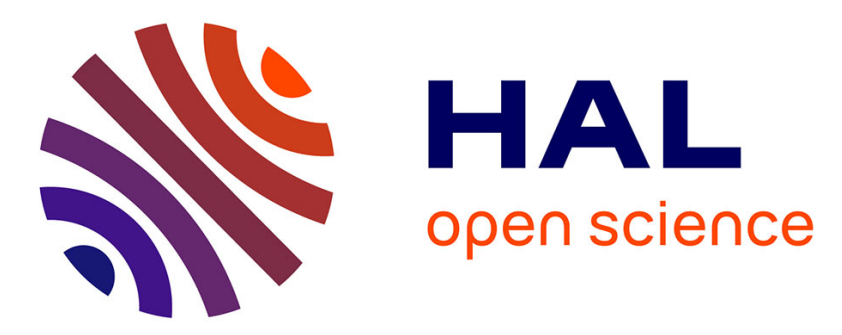

\title{
Unprecedented record of ten novel B chromosomes in the stingless bee Partamona helleri (Apidae, Meliponini)
}

Cinthia Martins, Ana Waldschmidt, Marco Costa

\section{To cite this version:}

Cinthia Martins, Ana Waldschmidt, Marco Costa. Unprecedented record of ten novel B chromosomes in the stingless bee Partamona helleri (Apidae, Meliponini). Apidologie, 2014, 45 (4), pp.431-439. 10.1007/s13592-013-0257-y . hal-01234736

\section{HAL Id: hal-01234736 \\ https://hal.science/hal-01234736}

Submitted on 27 Nov 2015

HAL is a multi-disciplinary open access archive for the deposit and dissemination of scientific research documents, whether they are published or not. The documents may come from teaching and research institutions in France or abroad, or from public or private research centers.
L'archive ouverte pluridisciplinaire HAL, est destinée au dépôt et à la diffusion de documents scientifiques de niveau recherche, publiés ou non, émanant des établissements d'enseignement et de recherche français ou étrangers, des laboratoires publics ou privés. 


\title{
Unprecedented record of ten novel B chromosomes in the stingless bee Partamona helleri (Apidae, Meliponini)
}

\author{
Cinthia Caroline Cardoso Martins ${ }^{1}$, Ana Maria WaldschmidT ${ }^{2}$, \\ Marco Antônio Costa ${ }^{1}$ \\ ${ }^{1}$ Departamento de Ciências Biológicas, Universidade Estadual de Santa Cruz, Rodovia Ilhéus-Itabuna, Km 16, \\ Ilhéus, Bahia, Brazil CEP 45662-900 \\ ${ }^{2}$ Departamento de Ciências Biológicas, Universidade Estadual do Sudoeste da Bahia, Rua Jose Moreira Sobrinho \\ s/n Jequiezinho, Jequié, Bahia, Brazil CEP 45206-510
}

Received 5 August 2013 - Revised 28 October 2013 - Accepted 14 November 2013

\begin{abstract}
Partamona helleri from southeastern Brazil has shown the presence of up to four minute supernumerary chromosomes of the B1 or B2 type and a numeric variation from $2 \mathrm{n}=34$ to 38 chromosomes. Since the maximum dosage of four of these Bs per individual has been observed, the existence of genetic mechanisms controlling their accumulation has been suggested. In this study, several new types of B chromosomes were found in other localities of the geographic distribution of this species, especially nearby the northern end of the species range, showing a numeric variation of $n=18$ to 19 in males and $2 n=34$ to $2 n=41$ in females. Ten novel types of acrocentric and metacentric B chromosomes were classified as B3 to B12. Eight types were found in the state of Bahia and two types in the state of Espírito Santo. The results suggest that these Bs have had different evolutionary mechanisms involved in their origin and diversification. A variation within and between geographic samples in the number of chromomycin A3 and Ag-NOR markings was observed as a result of the presence or absence of different Bs. Six different B chromosomes showed Ag-NOR markings, which denote presence of gene activity. The karyotype variation and the patterns of B chromosome distribution observed indicate that this species is likely undergoing a process of genetic differentiation.
\end{abstract}

stingless bee / geographical differentiation / B chromosome / Ag-NOR banding

\section{INTRODUCTION}

In stingless bees, $\mathrm{B}$ chromosomes have been reported in a few species such as Melipona rufiventris (Lopes et al. 2008), Tetragonisca fiebrigi (Barth et al. 2011), Partamona helleri-formerly named as Partamona cupira (Costa et al. 1992; Brito et al. 1997; Tosta et al. 2004; Martins et al. 2009), and P. cupira (Marthe et al. 2010). In the genus Partamona,

Corresponding author: M. A. Costa, costama@pq.cnpq.br

Manuscript editor: Klaus Hartfelder these chromosomes occur in addition to the standard karyotype, with $2 n=34$ chromosomes.

Previous cytogenetic analysis of $P$. helleri (Friese 1900) was mostly restricted to the state of Minas Gerais in southeastern Brazil, where two types of minute B chromosomes were found and classified as B1 and B2 by Brito et al. (1997). Tosta et al. (2004) reported the highest variation from one to four of these minute Bs per individual. Martins et al. (2009) found a new larger B chromosome (herein named B3 chromosome) in two locations of the state of Bahia, near the northernmost end of the species range.

Since in the previous studies there was no record of dosages higher than four B1 or B2 chromosomes 
per individual in this species, the existence of genetic mechanisms controlling their accumulation has been suggested by Costa et al. (1992) and Martins et al. (2012). Martins et al. (2012) also argued that potential constraints to higher accumulation would likely take place in the earlier instars of the bee larvae having more than four B chromosomes. Such effect, blocking their development in an earlier stage, would prevent B chromosome detection in the specimens, since the sampling stage for cytogenetic analysis in social stingless bees is technically limited to the fifth larval instar.

A number of different explanations have been proposed for the formation of B chromosomes in different organisms, e.g., as a byproduct chromosomal alterations in the regular karyotype (Camacho et al. 2000), formation from centric fragments by unequal translocation, or even as a byproduct of a hybridization process (Jones 1995; Jones et al. 2008). Martins et al. (2012) investigated the origin of B1 chromosome in populations of $P$. helleri from southeastern Brazil using microdissection and chromosome painting and found no homology with any of the regular chromosomes. This result can be interpreted as either due to an independent origin from the regular genome or that B1 chromosome has suffered substantial changes during the karyotype evolution process.

Camacho et al. (2000) pointed out that nucleolar organizer regions (NORs) could provide mechanisms for generating new $\mathrm{B}$ chromosomes. rRNA gene activity in B chromosomes has been found in both plants (Leach et al. 2005) and animals (Ruiz-Estévez et al. 2012). Brito et al. (2005) using $18 \mathrm{~S}$ rDNA in situ hybridization in $P$. helleri did not find presence of rDNA clusters in the B chromosomes. Martins et al. (2012) found similar result with Ag-NOR banding. In this study, we report several new types of $\mathrm{B}$ chromosomes and higher chromosome numbers in other localities of the geographic distribution of the species, especially nearby the northern end of the species range, which showed the highest karyotypic diversity. The new B chromosomes were analyzed and described using different cytogenetic techniques.

\section{MATERIALS AND METHODS}

We analyzed 20 individuals per colony. One colony was collected in Cruz das Almas (S12 $40^{\prime}$ / W $30^{\circ} 06^{\prime}$ ); two colonies in Itacaré, both localities are in the state of Bahia (S14 $\left.16^{\prime} / \mathrm{W} 38^{\circ} 59^{\prime}\right)$; and one colony in Santa Teresa, in the state of Espírito Santo $\left(\mathrm{S} 19^{\circ} 56^{\prime} / \mathrm{W} 40^{\circ} 36^{\prime}\right)$. The chromosome preparations were obtained from brain ganglion cells in the fifth larval instar, following Imai et al. (1988). C-banding was performed according to Sumner (1972) with modifications by Pompolo and Takahashi (1990). The location of nucleolar organizer regions using silver nitrate (Ag-NOR banding) was performed according to Howell and Black (1980) with modifications suggested by Kavalco and Pazza (2004). Fluorochrome staining (4',6-diamidino-2phenylindole (DAPI)/chromomycin A3 $\left(\mathrm{CMA}_{3}\right)$ ) was performed following Schweizer (1980). Fluorescence in situ hybridization (FISH) was performed using a 45S rDNA probe of Arabidopsis thaliana, according to Schwarzacher and HeslopHarrison (1999). The probe was labeled with cyanine 3-dUTP (Cy3) via nick translation (Invitrogen). The chromosomes were stained with DAPI. We analyzed 20 metaphase spreads per individual, and the best spreads were photographed in an Olympus CX-41 photomicroscope. Fluorescence images were captured in a Leica DRMA2 photomicroscope using IM50 software. The karyograms were organized following the methodology of Imai (1991) in decreasing order of size of euchromatic arms, using Adobe Photoshop CS4 version 11.0.2.

\section{RESULTS}

Present results revealed a higher variation in the chromosome number of $P$. helleri, which included males with $\mathrm{n}=18$ to 19 and females with $2 n=35$ to 41 chromosomes. This was caused by a variation in the presence/absence of ten different types of B chromosomes, varying in number from one to seven per individual (Table I). In the colony from Cruz das Almas (Figures 1a, 2a, 3a, and 4a, d), we found females with $2 n=35$ to $2 n=37$ and males with $n=18$ to $n=19$ chromosomes (Table I). In one colony from Itacaré (colony 1) (Figures 1b, 
$2 b, 3 b$, and $4 b$ ), we found a variation from $2 n=$ 36 to $2 n=39$ (Table I) and, in the other (colony 2) (Figures 1c, e, 2c, 3d, and 4c, e, f), a variation from $2 n=37$ to $2 n=41$. The colony from Santa Teresa (Figures 1d, 2d, and 3c) showed a numerical variation from $2 n=35$ to $2 n=36$ chromosomes.

The C-banding revealed metacentric chromosomes (sensu Imai 1991) in regular karyotype with heterochromatin distributed in the centromeric and pericentromeric regions of regular chromosomes (Figure 2). We also found morphological variation in regular chromosomes, which resulted in the three karyotypic formulae: $2 \mathrm{k}=4 \mathrm{M}^{\mathrm{ct}}+10 \mathrm{M}^{\mathrm{c}}+20 \mathrm{M}^{\mathrm{cc}}$ in Itacaré and $\mathrm{k}=$ $3 \mathrm{M}^{\mathrm{ct}}+5 \mathrm{M}^{\mathrm{c}}+9 \mathrm{M}^{\mathrm{cc}}$ in Cruz das Almas in the state of Bahia and $2 \mathrm{k}=10 \mathrm{M}^{\mathrm{c}}+24 \mathrm{M}^{\mathrm{cc}}$ in the samples from Espírito Santo (Table I, Figure 2).

The ten novel B chromosomes were classified in morphological types that could be arranged into acrocentrics (hereafter named B3, B4, B5, and B7) and metacentrics (B6, B8, B9, B10, B11, and B12) (Table II and Figures 1 and 2). The B3 chromosome classified here has been previously observed by Martins et al. (2009) in two other localities in the state of Bahia. The heterochromatin is distributed in almost the entire chromosome length, with euchromatin restricted to the chromosomal extremities on B4 and B5 (Figure $2 \mathrm{a}-\mathrm{c}$ ) and on B11 and B12 chromosomes (Figures 1d and 2d). The B chromosomes exhibited a high size variation from large, with length similar to regular chromosomes (B3, B4, B5, B6, B7, B11), to small B chromosomes (B8, B9, B10, B12) (Figures 1 and 2).

Fluorochrome staining showed a variation from five to eight $\mathrm{CMA}_{3}$ positive markings $\left(\mathrm{CMA}_{3}{ }^{+}\right)$that correspond to chromosome segments rich in GC base pairs (Figure 3 ). This variation was due to the presence of $\mathrm{CMA}_{3}$ markings mostly in the short arms on both $\mathrm{B}$ (Table II) and regular chromosomes. DAPI staining (Figure 3e) marked the centromeric and pericentromeric regions of all chromosomes showing that these heterochromatins are rich in AT base pairs.
The silver nitrate staining (Ag-NOR banding) in turn varied within and between geographic samples from 3 markings, as observed in a haploid male, to 11 positive markings as observed in a diploid female in the terminal regions of the chromosomes (Figure 4). In total, six different $\mathrm{B}$ chromosomes had terminal AgNOR markings (Table II and Figure 4). Fluorescence in situ hybridization using rDNA $45 \mathrm{~S}$ probe in colony 2 confirmed the presence of rDNa clusters (NORs) in B chromosomes (Figure 3).

A size heteromorphism was observed on the sixth chromosome pair in samples from Itacaré and Santa Teresa (Figure 1a, b, e). This heteromorphic segment had a long Ag-NOR positive block, which coincided with the $\mathrm{CMA}_{3}{ }^{+}$marking on the long arm (Figures 3c, $d$ and $4 b)$.

\section{DISCUSSION}

The record of seven $\mathrm{B}$ chromosomes per individual and the $2 n=41$ karyotype are the highest numbers so far found in a stingless bee. A total of ten morphological types of B chromosomes were reported in this study which differ substantially from what have been previously registered in southeastern Brazil, where only the minute B1 and B2 chromosomes were found (Brito et al. 1997).

The novel B chromosomes were characterized mainly by the large variation in number, size, and structure, including C-band patterns and molecular composition of the heterochromatin. The types and number of B chromosomes per individual varied geographically, having been found a greater variation and dosage in Itacaré in southern Bahia, with the occurrence of up to seven $B$ chromosomes per individual and the B3, B4, B5, B6, B7, B8, B9, and B10 chromosome types. On the other hand, individuals from Santa Teresa in the state of Espírito Santo showed only the types B1, B7, $\mathrm{B} 11$, and B12.

The high number of $\mathrm{B}$ chromosomes per specimen found in this study indicates a different pattern of tolerance to the accumula- 
Table I. Collecting locations, karyotypic formulae, number of Bs, and $\mathrm{CMA}_{3}$ or Ag-NOR markings on the regular and $\mathrm{B}$ chromosomes of $P$. helleri.

\begin{tabular}{llll}
\hline $\begin{array}{l}\text { Sampling } \\
\text { locations }\end{array}$ & $\begin{array}{l}\text { Karyotypic formulae } \\
\text { (A chromosomes) }\end{array}$ & $\begin{array}{l}\text { Number of B chromosome } \\
\text { per individual }\end{array}$ & B chromosome type \\
\hline $\begin{array}{lll}\text { Itacaré-BA (1) } \\
\text { Itacaré-BA (2) }\end{array}$ & $2 \mathrm{k}=4 \mathrm{M}^{\mathrm{ct}}+10 \mathrm{M}^{\mathrm{c}}+20 \mathrm{M}^{\mathrm{cc}}$ & $2,3,4$, or 5 & B4 B5 B6 B9 B10 \\
& $2 \mathrm{k}=4 \mathrm{M}^{\mathrm{ct}}+10 \mathrm{M}^{\mathrm{c}}+20 \mathrm{M}^{\mathrm{cc}}$ & $3,5,6$, or 7 & B3 B4 B5 B6 B7 \\
Cruz das Almas-BA & $\mathrm{k}=3 \mathrm{M}^{\mathrm{ct}}+5 \mathrm{M}^{\mathrm{c}}+9 \mathrm{M}^{\mathrm{cc}}$ & 1,2 , or 3 & B8 B9 B10 \\
Santa Teresa-ES & $2 \mathrm{k}=10 \mathrm{M}^{\mathrm{c}}+24 \mathrm{M}^{\mathrm{cc}}$ & 1 or 2 & B4 B5 B6 B9 B10 \\
\hline
\end{tabular}

tion of these newly described B chromosomes. This observation reinforces the genetic differences of these chromosomes when compared to the minute B chromosomes previously recorded in southeast Brazil, for which Martins et al. (2012) suggested the existence of cytogenetic or genetic constraints in establishing karyotypes with high $\mathrm{B}$ numbers.
The samples from Northeast region showed some B chromosomes with size comparable to the largest chromosomes in the regular karyotype, as well as smaller Bs (Figures 1 and 2). The record of one large $\mathrm{B}$ chromosome in $P$. helleri was first made by Martins et al. (2009) in two localities near the northern end of the species distribution, in the state of Bahia.

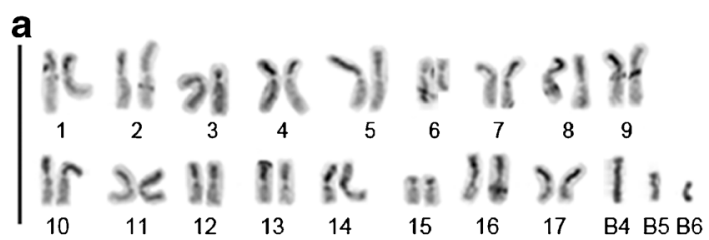

b
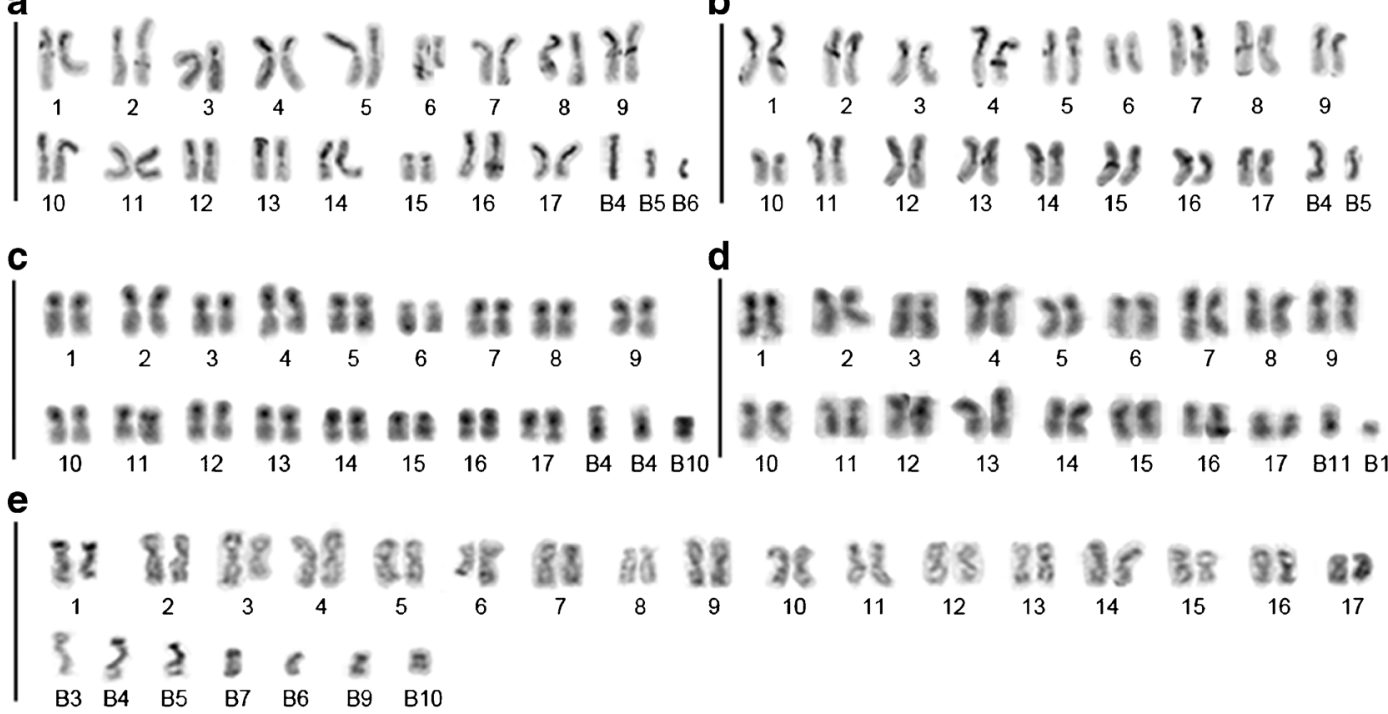

Figure 1. Karyotype of $P$. helleri submitted to Giemsa staining: a female from Cruz das Almas, BA with $2 \mathrm{n}=$ $34+3 \mathrm{~B}$; b female from Itacaré, BA (colony 1 ) with $2 \mathrm{n}=34+2 \mathrm{~B}$; $\mathbf{c}$ female from Itacaré, BA (colony 2 ) with $2 \mathrm{n}=$ $34+3 B$; d female from Santa Teresa, ES with $2 n=34+2 B$; and $\mathbf{e}$ female from Itacaré, BA, colony 2 with $2 n=$ $34+7 \mathrm{~B}$ (metaphase submitted to Ag-NOR staining). Heteromorphism in the sixth chromosome pair of regular karyotype is shown in $\mathbf{a}, \mathbf{b}$, and $\mathbf{e}$. The bar represents $10 \mu \mathrm{m}$. 

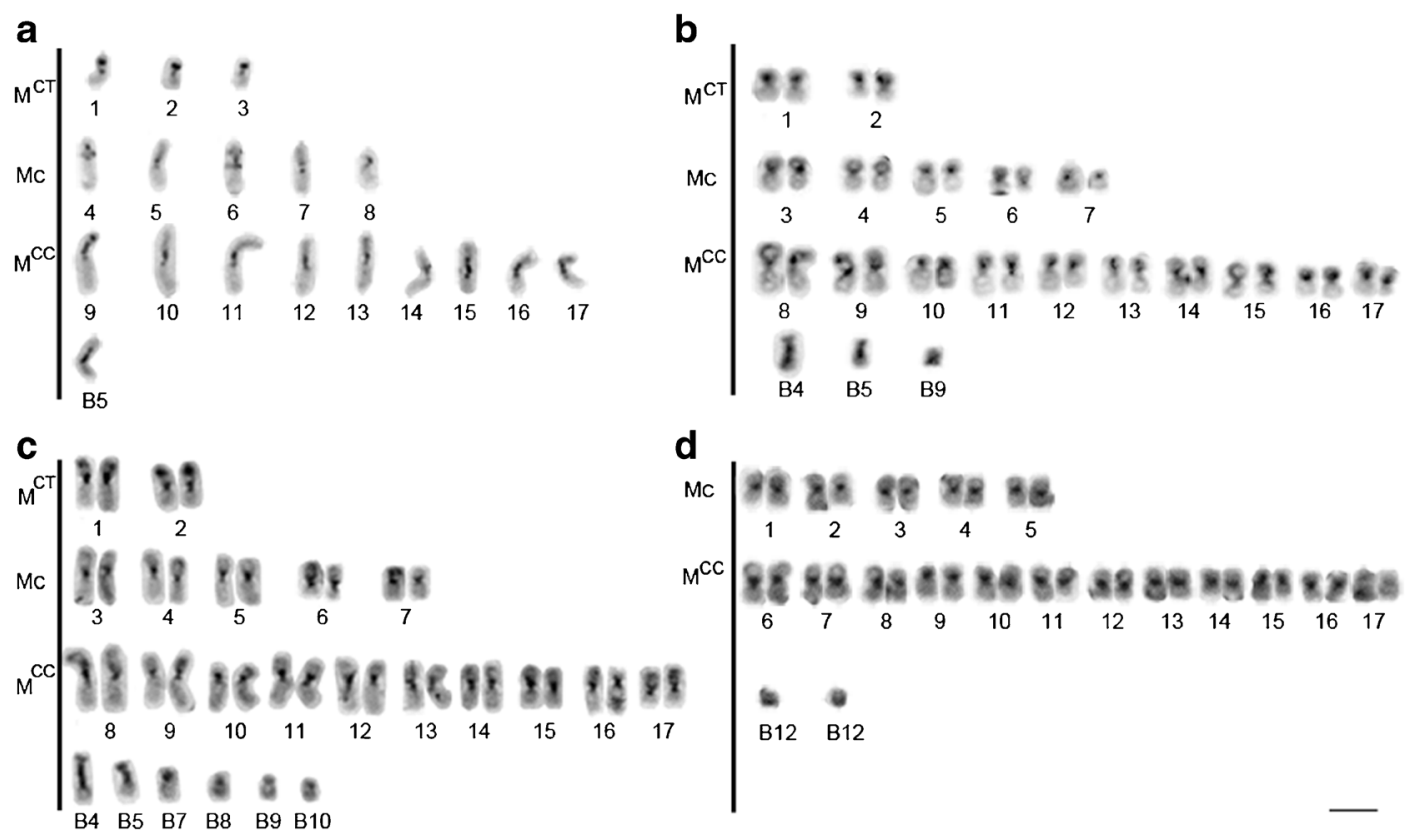

Figure 2. Karyotype of $P$. helleri submitted to C-banding: a male from Cruz das Almas, BA with $\mathrm{n}=17+1 \mathrm{~B}$; b female from Itacaré, BA (colony 1) with $2 \mathrm{n}=34+3 \mathrm{~B}$, c female from Itacaré, BA (colony 2) with $2 \mathrm{n}=34+6 \mathrm{~B}$; and $\mathbf{d}$ female Santa Teresa, ES with $2 \mathrm{n}=34+2 \mathrm{~B}$. The bar represents $10 \mu \mathrm{m}$.

Likewise, a large B chromosome with a short arm rich in GC base pairs was described by Marthe et al. (2010) in a closely related species, $P$. cupira which showed morphological similarity with B4 and B5 types found in P. helleri. Camargo and Pedro (2003) suggest that $P$. helleri is a sister group of the "termitophilous" Partamona species, being closely related to the cupira group (Partamona aylae, Partamona littoralis, Partamona sooretamae, Partamona criptica, Partamona rustica, Partamona mulata, Partamona seridoenses, P. cupira). Considering the proximity between these species, a possible homeology between these similar B chromosomes must be further investigated.

The expressive variation within and between geographic samples in the number of Ag-NOR and $\mathrm{CMA}_{3}{ }^{+}$markings was mainly due to the presence or absence of $\mathrm{B}$ chromosomes carrying these markings in the individuals. Six distinct types of Bs carrying ribosomal sites were found.
Since silver staining can be indicative of ribosomal gene activity (Hubbell 1985), presence of additional active NORs can provide selective advantage for B-carriers (Beukeboom 1994) and favor the maintenance of these $\mathrm{B}$ chromosomes in the population. B chromosomes with rDNA clusters have been observed in diverse animal species such as the grasshopper Eyprepocnemis plorans (Cabrero et al. 1987; López-León et al. 1991; Ruiz-Estévez et al. 2012), the anuran Leiopelma hochstetteri (Green 1988), and the rodent Apodemus peninsulae (Boeskorov et al. 1995) and in plants (Crepis capillaris) (Leach et al. 2005), among others.

Although microdissection analysis of the minute $\mathrm{B} 1$ chromosome in $P$. helleri populations from southeastern Brazil was inconclusive about its origin, Martins et al. (2012) suggested either an independent origin from the rest of the genome or the occurrence of substantial changes in the chromosomal segment during its process of evolution in the karyotype. The 


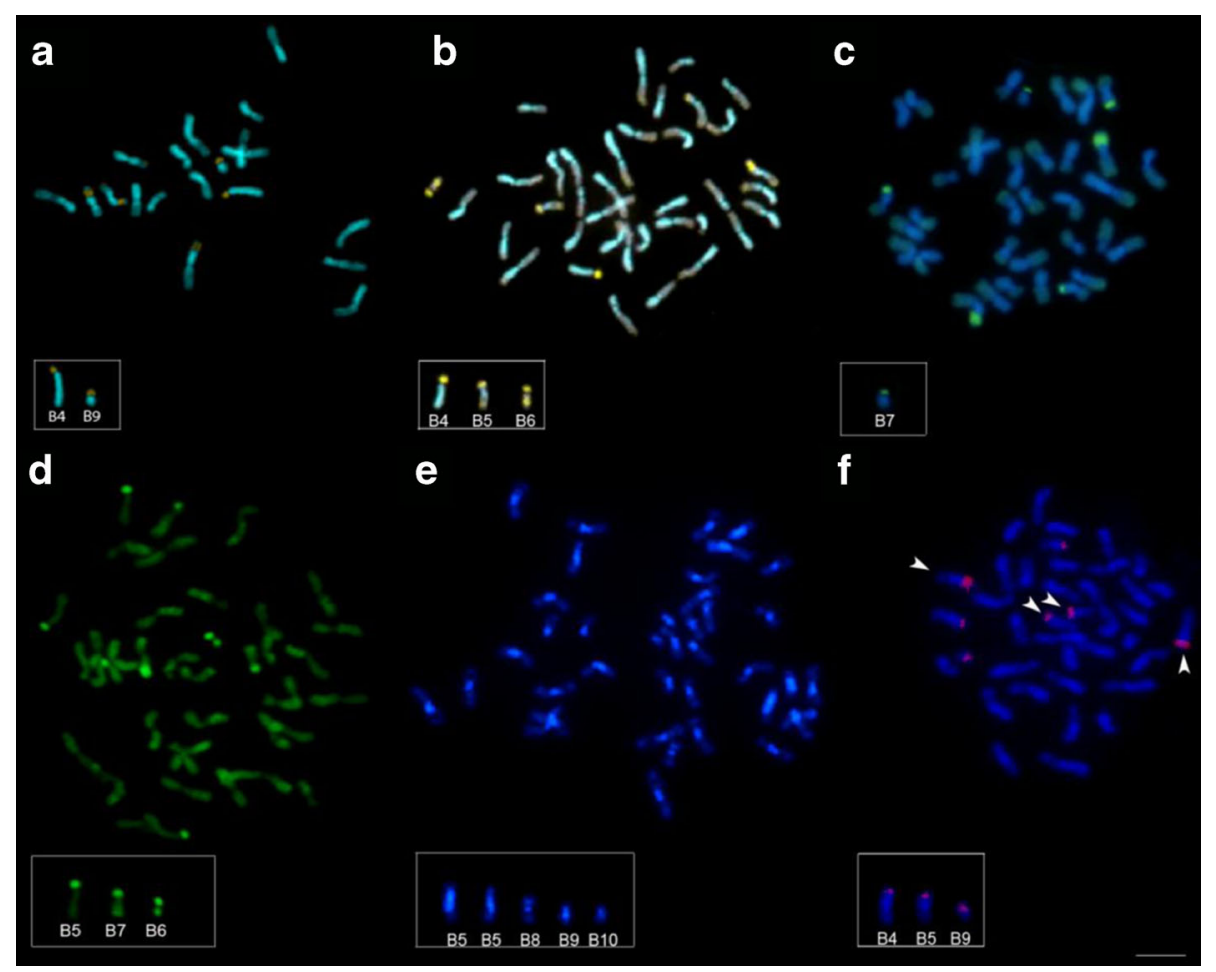

Figure 3. Metaphases of $P$. helleri stained with $\mathrm{DAPI} / \mathrm{CMA}_{3}$ : a male from Cruz das Almas, BA with $\mathrm{n}=17+$ $2 \mathrm{~B}$; b female from Itacaré, BA (colony 1 ) with $2 n=34+3 B$; c female Santa Teresa, ES with $2 n=34+1 B$; d $\mathrm{CMA}_{3}$ staining in female from in Itacaré, Bahia (colony 2) with $2 \mathrm{n}=34+5 \mathrm{~B}$; and e DAPI staining in female from Itacaré, BA (colony 2) with $2 \mathrm{n}=34+5 \mathrm{~B}$. Metaphase submitted to rDNA $45 \mathrm{~S}$ FISH: $\mathbf{f}$ female from Itacaré, BA (colony 2) with $2 n=39$. The B chromosomes marked with DAPI, $\mathrm{CMA}_{3}$, or rDNA 45S FISH are detached in each metaphase. The arrowheads indicate regular heteromorphic chromosome with rDNA blocks. The bar represents $10 \mu \mathrm{m}$.

novel set of $\mathrm{B}$ chromosomes of $P$. helleri, especially those in the samples from Bahia, does not seem to share a common origin and their structural differences suggest the existence of different evolutionary mechanisms involved in their origin and diversification. The mention that the rDNA clusters are prone to breakage and provide mechanism for $\mathrm{B}$ chromosome formation (Camacho et al. 2000), and the discovery of such clusters in six of the B chromosomes reaffirms this as a likely mechanism involved in the formation of some Bs carrying NORs. Subsequent rearrangements involving the existing B chromosomes may have generated variants in the population.
The similarity between the B4 and B5 chromosomes, for example, suggests that these chromosomes are variant forms resulting from small structural changes in the interstitial heterochromatin content. Bakkali and Camacho (2004) in studies of grasshopper, Eyprepocnemis plorans, revealed 16 variants for B chromosomes in nine populations from Morocco, many being derived from the other Bs. Among the mutations involved in the process are rDNA deletion, translocations, duplications, and chromatid nondisjunction with consequent formation of isochromosomes.

Another relevant aspect observed in the karyotypes of $P$. helleri was the geographical variation 


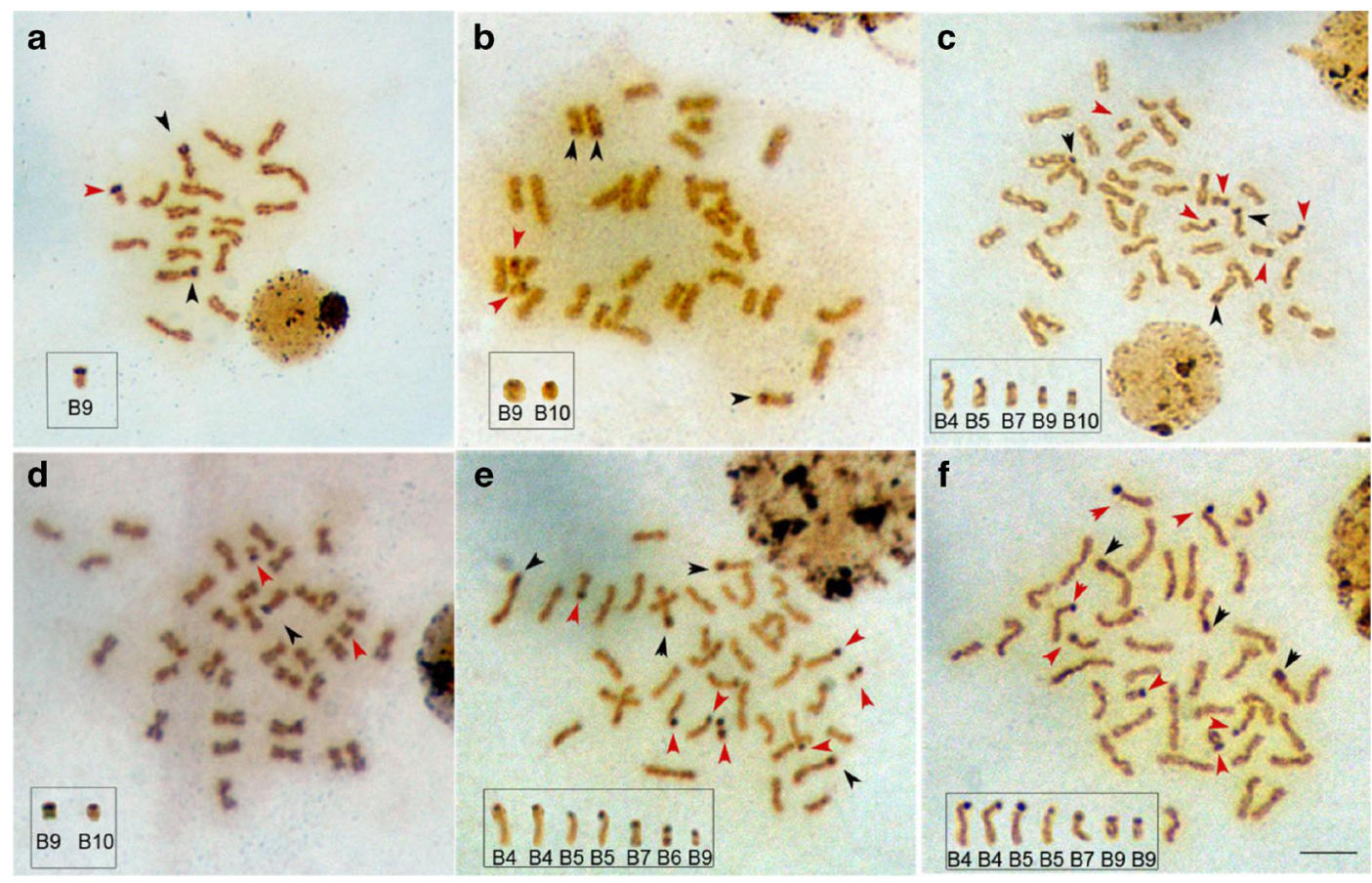

Figure 4. Ag-NOR staining in metaphase of $P$. helleri: $\mathbf{a}, \mathbf{d}$ male and female from Cruz das Almas, BA with $\mathrm{n}=$ $17+1 B$ and $2 n=34+2 B$, respectively; b female from Itacaré, BA (colony 1 ) with $2 n=34+2 B$; c, e, f female from Itacaré, BA (colony 2) with $2 \mathrm{n}=34+5 \mathrm{~B}$ or $2 \mathrm{n}=34+7 \mathrm{~B}$. B chromosomes stained with Ag-NOR are detached in each metaphase. Black and red arrowheads indicate Ag-NOR markings on regular and B chromosomes, respectively. The bar represents $10 \mu \mathrm{m}$.

Table II. P. helleri B chromosome characterization by different cytogenetic techniques.

\begin{tabular}{|c|c|c|c|c|c|}
\hline $\begin{array}{l}\text { B chromosome } \\
\text { type }\end{array}$ & $\begin{array}{l}\text { Karyotypic } \\
\text { description }\end{array}$ & Heterochromatin & Euchromatin & $\begin{array}{l}\mathrm{CMA}_{3} \\
\text { staining }\end{array}$ & $\begin{array}{l}\text { Ag-NOR } \\
\text { banding }\end{array}$ \\
\hline B1 & - & + & - & - & - \\
\hline B2 & A & + & $-^{\mathrm{a}}$ & - & $-^{\mathrm{a}}$ \\
\hline B3 & A & + & - & + & $-^{\mathrm{a}}$ \\
\hline B4 & $\mathrm{A}$ & + & + & + & + \\
\hline B5 & A & + & + & + & + \\
\hline B6 & $\mathrm{M}$ & + & + & + & + \\
\hline B7 & $\mathrm{A}$ & + & + & + & + \\
\hline B8 & $\mathrm{M}$ & + & + & $-^{\mathrm{a}}$ & $-^{\mathrm{a}}$ \\
\hline B9 & $\mathrm{M}$ & + & + & + & + \\
\hline B10 & M & + & + & + & + \\
\hline B11 & $\mathrm{M}$ & + & + & $-^{\mathrm{a}}$ & $-^{\mathrm{a}}$ \\
\hline B12 & $\mathrm{M}$ & + & + & $-^{\mathrm{a}}$ & $-^{\mathrm{a}}$ \\
\hline
\end{tabular}

+ and - indicate positive and negative response to treatment, respectively. B1 and B2 morphology followed Brito et al. (1997). B1 and B2 fluorochrome data followed Brito et al. (2005) and Martins et al. (2012)

${ }^{\mathrm{a}}$ Data not analyzed 
in the regular karyotype characterized by the presence or absence of a $\mathrm{M}^{\mathrm{ct}}$ chromosome pair (Figure 2). Furthermore, the length heteromorphism observed in the sixth chromosome pair differed from that of Brito et al. (1997, 2005) which showed a heteromorphism in the second pair. Length heteromorphisms can be formed by translocations, unequal crossing over, and heterochromatin tandem growth or deletion (Hatanaka et al. 1998). These and other variations found in the regular chromosomes of $P$. helleri may be involved in the origin of some of the Bs found in different geographic regions, and the several pieces of evidence of chromosome rearrangements found suggest a high level of restructuring in the regular karyotype in this species.

From these and previous results, it is apparent that $P$. helleri shows B chromosomes differentiated by geographical regions in accordance with the distribution pattern of the species, with more B chromosomes varying in size, morphology, and dosage in $P$. helleri population from the state of Bahia, the northernmost part of the species range, when compared to those obtained in $P$. helleri populations from Espírito Santo and Minas Gerais.

The diversity of B chromosomes can be used as a model to understand the dynamics of these populations and the mechanisms involved in the karyotype evolution. The karyotype variation and the patterns of $\mathrm{B}$ chromosome distribution indicate that this species is likely undergoing a process of genetic differentiation. More detailed studies must be developed to determine the probable center of origin of B chromosomes, the different mechanisms involved in their origin, and the presence of transcriptional gene activity. Within this perspective, the fact that regular and $\mathrm{B}$ chromosomes contain $\mathrm{rDNA}$ is a good start for further investigations of their origin.

\section{ACKNOWLEDGMENTS}

We thank Dr. Silvia RM Pedro for the specimen identification. This study was supported by CAPES (Coordenadoria de Aperfeiçoamento de Pessoal de
Nível Superior) and CNPq (Conselho Nacional de Desenvolvimento Científico e Tecnológico).

Observation inédite de $\mathbf{1 0}$ nouveaux chromosomes B chez l'abeille sans aiguillon Partamona helleri (Apidae, Meliponini)

\section{Abeille sans aiguillon / différenciation géographique / chromosome B / bandes Ag-NOR}

Ein unerwarteter Befund mit zehn neuen BChromosomen bei der stachellosen Biene Partamona helleri (Apidae, Meliponini)

Stachellose Biene / geographische Differenzierung / BChromosom / Ag-NOR

\section{REFERENCES}

Bakkali, M., Camacho, J.P.M. (2004) The B chromosome polymorphism of the grasshopper Eyprepocnemis plorans in North Africa: III. Mutation rate of B chromosomes. Heredity 92, 428-433

Barth, A., Fernandes, A., Pompolo, S.G., Costa, M.A. (2011) Occurrence of B chromosomes in Tetragonisca Latreille, 1811 (Hymenoptera, Apidae, Meliponini): a new contribution to the cytotaxonomy of the genus. Genet Mol Biol 34(1), 77-79

Beukeboom, L.W. (1994) Bewildering Bs: an impression of the 1 st B chromosome conference. Heredity 73, 328-336

Boeskorov, G.C., Kartavtseva, I.V., Zagorodnyuk, I.V., Belyanin, A.N., Lyapunova, E.A. (1995) Nucleolus organizer regions and B chromosomes of wood mice (Mammalia, Rodentia, Apodemus). Russ J Genet 31(2), 156-163

Brito, R.M., Costa, M.A., Pompolo, S.G. (1997) Characterization and distribution of supernumerary chromosomes in 23 colonies of Partamona helleri (Hymenoptera, Apidae, Meliponinae). Brazil. J. Genet. 20(2), 185-188

Brito, R.M., Pompolo, S.G., Magalhães, M.F.M., Barros, E.G., Hojo, E.T.S. (2005) Cytogenetic characterization of two Partamona species (Hymenoptera, Apinae, Meliponini) by fluorochrome staining and localization of $18 \mathrm{~S}$ rDNA clusters by FISH. Cytologia 70, 373-380

Cabrero, J., Alché, J.D., Camacho, J.P.M. (1987) Effects of $\mathrm{B}$ chromosomes of the grasshopper Eyprepocnemis plorans on nucleolar organizer regions activity. Activation of a latent NOR on a B chromosome fused to an autosome. Genome 29, 116-121

Camacho, J.P.M., Sharbel, T.F., Beukeboom, L.W. (2000) B chromosome evolution. Phil. Trans. R. Soc. Lond. B 355, 163-178 
Camargo, J.M.F., Pedro, S.R.M. (2003) Meliponini neotropicais: o gênero Partamona Schwarz, 1939 (Hymenoptera, Apidae, Apinae) - bionomia e biogeografia. Rev. Bras. Entomol. 47, 311-372

Costa, M.A., Pompolo, S.G., Campos, L.A.O. (1992) Supernumerary chromosomes in Partamona cupira (Hymenoptera, Apidae, Meliponinae). Rev. Bras. Genet. 15, 801-806

Green, D.M. (1988) Cytogenetics of the endemic New Zealand frog, Leiopelma hochstetteri: extraordinary supernumerary chromosome variation and a unique sex-chromosome system. Chromosoma 97, 55-70

Hatanaka, T., Tambasco, A.J., Galetti-Junior, P.M. (1998) Heterochromatin heterogeneity and chromosome heteromorphism in Cerdocyon thous (Mammalia, Canidae). Genet Mol Biol 21, 227-231

Howell, W.M., Black, D.A. (1980) Controlled silverstaining of nucleolus organizer regions with a protective colloidal developer: a 1-step method. Experientia 36, 1014-1015

Hubbell, H.R. (1985) Silver staining as an indicator of active ribosomal genes. Stain Technol 60(5), 285-294

Imai, H.T. (1991) Mutability of constitutive heterochromatin (C-bands) during eukaryotic chromosomal evolution and their cytological meaning. Jpn J Genet 66, 635-661

Imai, H.T., Taylor, R.W., Crosland, M.W., Crozier, R.H. (1988) Modes of spontaneous chromosomal mutation and karyotype evolution in ants with reference to the minimum interaction hypothesis. Jpn J Genet 63, 159-185

Jones, R.N. (1995) Tansley review no. 85: B chromosomes in plants. New Phytol 131, 411-434

Jones, R.N., Viegas, W., Houben, A. (2008) A century of B chromosomes in plants: so what? Ann Bot 101, 767-775

Kavalco, K.F., Pazza, R. (2004) A rapid alternative technique for obtaining silver positive patterns in chromosomes. Genet Mol Biol 27, 196-198

Leach, C.R., Houben, A., Field, B., Pistrick, K., Demidov, D., Timmis, J.N. (2005) Molecular evidence for transcription of genes on a B chromosome in Crepis capillaris. Genetics 171, 269-278

Lopes, D.M., Pompolo, S.G., Campo, L.A.O., Tavares, M.G. (2008) Cytogenetic characterization of Melipona rufiventris Lepeletier 1836 and Melipona mondury Smith 1863 (Hymenoptera, Apidae) by C banding and fluorochromes staining. Genet Mol Biol 31(1), 49-52

López-León, M.D., Cabrero, J., Camacho, J.P.M. (1991) A nucleolus organizer region in a $\mathrm{B}$ chromosome inactivated by DNA methylation. Chromosoma 100, 134-138

Marthe, J.B., Pompolo, S.G., Campos, L.A.O., Salomão, T.M.F., Tavares, M.G. (2010) Cytogenetic characterization of Partamona cupira (Hymenoptera, Apidae) by fluorochromes. Genet Mol Biol 33, 253-255

Martins, C.C.C., Diniz, D., Sobrinho-Scudeler, P.E., Foresti, F., Campos, L.A.O., Costa, M.A. (2012) Investigation of Partamona helleri (Apidae, Meliponini) B chromosome origin. An approach by microdissection and whole chromosome painting. Apidologie 44, 75-81

Martins, C.C.C., Duarte, O.M.P., Waldschmidt, A.M., Alves, R.M.O., Costa, M.A. (2009) New occurrence of $\mathrm{B}$ chromosomes in Partamona helleri (Friese, 1900) (Hymenoptera, Meliponini). Genet Mol Biol 32, 782-785

Pompolo, S.G., Takahashi, C.S. (1990) Chromosome numbers and C-banding in two wasp species of the genus Polistes (Hymenoptera Polistine, Polistini). Insectes Soc. 37, 251-257

Ruiz-Estévez, M., López-León, M.D., Cabrero, J., Camacho, J.P.M. (2012) B-chromosome ribosomal DNA is functional in the grasshopper Eyprepocnemis plorans. PLoS ONE . doi:10.1371/ journal.pone. 0036600

Schwarzacher, T., Heslop-Harrison, P. (1999) Practical in situ hybridization. BIOS Scientific, Oxford

Schweizer, D. (1980) Simultaneous fluorescent staining of $\mathrm{R}$ bands and specific heterochromatic regions (DA-DAPI bands) in human chromosomes. Cytogenet Cell Genet 27, 190-193

Sumner, A.T. (1972) A simple technique for demonstrating centromeric heterochromatin. Exp Cell Res 75, 304-306

Tosta, V.C., Fernandes-Salomão, T.M., Tavares, M.G., Pompolo, S.G., Barros, E.G., Campos, L.A.O. (2004) A RAPD marker associated with B chromosomes in Partamona helleri (Hymenoptera, Apidae). Cytogenet. Genome Res. 106, 279-283 